NASA/TM-2009-215519

Concept, Simulation, and Instrumentation for Radiometric Inflight Icing Detection

Charles C. Ryerson and George G. Koenig

Cold Regions Research and Engineering Laboratory, Hanover, New Hampshire

Andrew L. Reehorst

Glenn Research Center, Cleveland, Ohio

Forrest R. Scott

Sensor Concepts and Applications, Inc., Phoenix, Maryland 


\section{NASA STI Program . . . in Profile}

Since its founding, NASA has been dedicated to the advancement of aeronautics and space science. The NASA Scientific and Technical Information (STI) program plays a key part in helping NASA maintain this important role.

The NASA STI Program operates under the auspices of the Agency Chief Information Officer. It collects, organizes, provides for archiving, and disseminates NASA's STI. The NASA STI program provides access to the NASA Aeronautics and Space Database and its public interface, the NASA Technical Reports Server, thus providing one of the largest collections of aeronautical and space science STI in the world. Results are published in both non-NASA channels and by NASA in the NASA STI Report Series, which includes the following report types:

- TECHNICAL PUBLICATION. Reports of completed research or a major significant phase of research that present the results of NASA programs and include extensive data or theoretical analysis. Includes compilations of significant scientific and technical data and information deemed to be of continuing reference value. NASA counterpart of peer-reviewed formal professional papers but has less stringent limitations on manuscript length and extent of graphic presentations.

- TECHNICAL MEMORANDUM. Scientific and technical findings that are preliminary or of specialized interest, e.g., quick release reports, working papers, and bibliographies that contain minimal annotation. Does not contain extensive analysis.

- CONTRACTOR REPORT. Scientific and technical findings by NASA-sponsored contractors and grantees.

- CONFERENCE PUBLICATION. Collected papers from scientific and technical conferences, symposia, seminars, or other meetings sponsored or cosponsored by NASA.

- SPECIAL PUBLICATION. Scientific, technical, or historical information from NASA programs, projects, and missions, often concerned with subjects having substantial public interest.

- TECHNICAL TRANSLATION. Englishlanguage translations of foreign scientific and technical material pertinent to NASA's mission.

Specialized services also include creating custom thesauri, building customized databases, organizing and publishing research results.

For more information about the NASA STI program, see the following:

- Access the NASA STI program home page at http://www.sti.nasa.gov

- E-mail your question via the Internet to help@ sti.nasa.gov

- Fax your question to the NASA STI Help Desk at 301-621-0134

- Telephone the NASA STI Help Desk at 301-621-0390

- Write to: NASA Center for AeroSpace Information (CASI) 7115 Standard Drive Hanover, MD 21076-1320 
NASA/TM-2009-215519

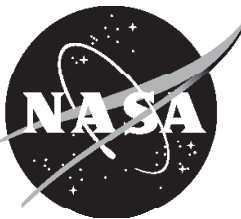

\section{Concept, Simulation, and Instrumentation for Radiometric Inflight Icing Detection}

Charles C. Ryerson and George G. Koenig

Cold Regions Research and Engineering Laboratory, Hanover, New Hampshire

Andrew L. Reehorst

Glenn Research Center, Cleveland, Ohio

Forrest R. Scott

Sensor Concepts and Applications, Inc., Phoenix, Maryland

National Aeronautics and

Space Administration

Glenn Research Center

Cleveland, Ohio 44135 


\section{Acknowledgments}

This research is in response to requirements and funding by NASA and the Army Corps of Engineers. NASA support originates from the Aviation Safety Program and was managed by NASA Glenn Research Center. Corps of Engineers funding originated at Engineer Research and Development Center-Cold Regions Research and Engineering Laboratory. The authors thank Sierra Nevada Corporation and their Waveband Business Unit and Ben Bernstein of Leading Edge Atmospherics LLC for polarimeter flights and weather guidance during flights. Views expressed are those of the authors and do not necessarily represent the official policy or position of NASA or of the Corps of Engineers.

Level of Review: This material has been technically reviewed by technical management.

Available from

NASA Center for Aerospace Information 7115 Standard Drive

Hanover, MD 21076-1320
National Technical Information Service 5285 Port Royal Road Springfield, VA 22161

Available electronically at http://gltrs.grc.nasa.gov 


\title{
Concept, Simulation, and Instrumentation for Radiometric Inflight Icing Detection
}

\author{
Charles C. Ryerson and George G. Koenig \\ Cold Regions Research Engineering Laboratory \\ Hanover, New Hampshire 03755 \\ Andrew L. Reehorst \\ National Aeronautics and Space Administration \\ Glenn Research Center \\ Cleveland, Ohio 44135 \\ Forrest R. Scott \\ Sensor Concepts and Applications, Inc. \\ Phoenix, Maryland 21131
}

\begin{abstract}
The multi-agency Flight in Icing Remote Sensing Team (FIRST), a consortium of the National Aeronautics and Space Administration (NASA), the Federal Aviation Administration (FAA), the National Center for Atmospheric Research (NCAR), the National Oceanographic and Atmospheric Administration (NOAA), and the Army Corps of Engineers (USACE), has developed technologies for remotely detecting hazardous inflight icing conditions. The USACE Cold Regions Research and Engineering Laboratory (CRREL) assessed the potential of onboard passive microwave radiometers for remotely detecting icing conditions ahead of aircraft. The dual wavelength system differences the brightness temperature of Space and clouds, with greater differences potentially indicating closer and higher magnitude cloud liquid water content (LWC). The Air Force RADiative TRANsfer model (RADTRAN) was enhanced to assess the flight track sensing concept, and a "flying" RADTRAN was developed to simulate a radiometer system flying through simulated clouds. Neural network techniques were developed to invert brightness temperatures and obtain integrated cloud liquid water. In addition, a dual wavelength Direct-Detection Polarimeter Radiometer (DDPR) system was built for detecting hazardous drizzle drops. This paper reviews technology development to date and addresses initial polarimeter performance.
\end{abstract}

\section{INTRODUCTION}

Aircraft with operating ice protecting systems have crashed, suggesting that certified ice protection systems are not adequate for all conditions. The most effective protection from icing is still avoidance; provided by icing analysis and forecast tools such as the Current Icing Product (CIP) and the Forecast Icing Potential (FIP) models for example ${ }^{1}$. However, pilots still encounter dangerous icing conditions because knowledge of the atmosphere is not perfect and icing analysis and forecast tools are more challenged in areas of complex terrain. In addition, certain classes of aircraft such as helicopters and turboprops that operate at altitudes favorable for icing typically have limited on-board ice protection systems. Unlike most jets, which encounter icing primarily during departure and approach, turboprops and helicopters are also often immersed in icing conditions during cruise.

FIRST has evaluated the potential for remotely sensing icing conditions, and has developed a variety of groundbased and airborne concepts and prototypes. Icing remote sensing systems operate by detecting the conditions that cause aircraft icing, temperature and cloud LWC. Icing does not occur until supercooled droplets collide with and freeze upon aircraft surfaces. Therefore, icing remote sensing systems only sense icing potential.

A variety of sensing modalities can be used to remotely sense icing conditions ahead of aircraft. One approach is to use aircraft-mounted passive microwave radiometry because of the potential for lower cost and smaller size and the potential for protecting smaller aircraft that frequently encounter icing conditions during cruise. This paper describes the development of passive inflight detection by ERDC-CRREL, the current state of the program, and preliminary results from early flight tests of prototype instrumentation. 


\section{CONCEPTS}

Microwave radiometers receive thermal energy emitted and scattered by components of the Earth's atmosphere. Each atmospheric gaseous component has a unique absorption spectrum. The atmospheric gases absorb in several narrow wavelength bands and allow radiation to be transmitted through several atmospheric windows. The primary absorbers are oxygen, water vapor, and liquid water. Oxygen absorbs and re-emits around 50 to $60-\mathrm{GHz}$ and at 118 $\mathrm{GHz}$ and is used for creating temperature soundings. Water vapor absorbs and re-emits at 22, 37, and $183 \mathrm{GHz}$, and liquid water near $37 \mathrm{GHz}$ and $89 \mathrm{GHz}^{2}$. These absorption and emission peaks provide guidance for selecting the appropriate radiometer frequencies for detecting atmospheric gases and liquids. In addition, the dielectric strength, or permittivity, of the substance effects how easily detection can occur. For example, ice has a permittivity approximately $10 \%$ of that of water in the millimeter wave spectrum. Therefore, the brightness temperature of water clouds will tend to be greater than the brightness temperature of ice clouds.

In this application, passive microwave radiometers must measure atmospheric temperature, cloud liquid-water content, and attributes of cloud and precipitation constituents needed for estimating icing hazards. The radiometer measures photons resulting from emission, transmission, and scattering. The radiometer information provided is the brightness temperature. This requires a calibrated system. In addition, we can measure polarization information if our radiometer design permits. From these measurements we infer the other information; the radiometer does not directly measure LWC and the other information required. Since we are interested in observing the radiative characteristics of cloud droplets and drizzle drops, we are operating at $35 \mathrm{GHz}$ and $94 \mathrm{GHz}$ within and near the absorption and emission spectra of liquid water, and within windows where, by international agreement, there is little radio-frequency interference. Because water vapor is potentially distributed non-uniformly in the clear atmosphere outside the cloud, and it also absorbs and reemits at $37 \mathrm{GHz}$, the behavior of the sensor will also vary within and between flight levels as water vapor content changes ${ }^{3}$.

Passive microwave detection of cloud water and precipitation is commonly achieved using ground-based sensors that look to zenith and observe the brightness difference between clouds that exhibit high brightness temperatures, and space that exhibits a low brightness temperature. This has been demonstrated in numerous field studies, including the Mt. Washington Icing Sensors Project (MWISP) and the Alliance Icing Research Study programs I and II ${ }^{4,5}{ }^{6}$. Conversely, satellite-borne radiometers looking nadir can detect cloud water and rainfall rates over water bodies because like space they also provide a low brightness temperature background due to low MMW emissivity of water.

Contrary to other passive microwave applications, aircraft mounted radiometers must scan nearly-horizontally along the aircraft flight path to detect icing conditions. In addition, unless gimbaled to provide directional control, aircraft-mounted microwave radiometers will view toward space during departure, or view toward the Earth's surface during approach, which can be land-or water-covered, making the detection of cloud supercooled water more challenging. We show examples of some of these effects later in this paper with ungimbaled instruments.

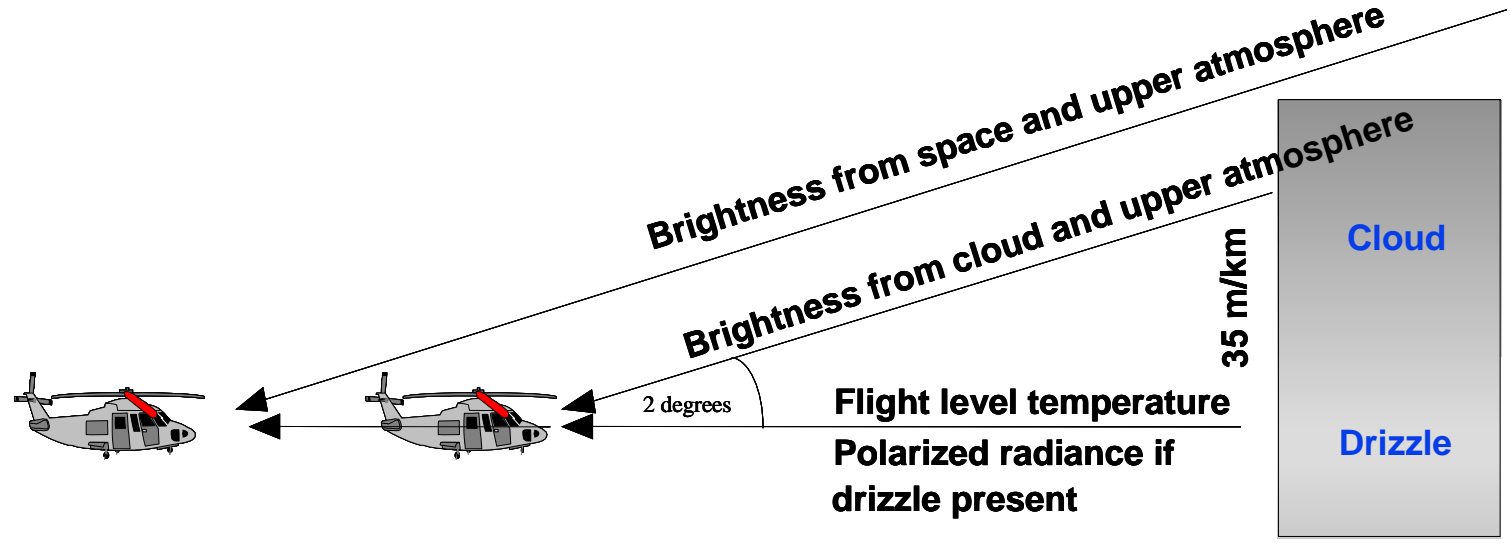

Fig 1. Liquid water and large drop sensing scheme ${ }^{3}$. 
To address some of these difficulties, we use a variation of a method presented by Savage et al. ${ }^{3}$ for locating and estimating icing conditions using two frequencies sensitive to LWC, 37 and $89 \mathrm{GHz}$, and two viewing angles (Fig. 1). Nose-mounted radiometers scan ahead of the aircraft horizontally and 2 degrees above horizontal. In a clear-sky condition, the +2 degree beam detects colder temperatures by viewing cold space than does the horizontal beam looking forward through a greater depth of atmosphere. Since the atmosphere is more transmissive at $37 \mathrm{GHz}$ than at $89 \mathrm{GHz}$, the brightness temperature of the +2 degree $37 \mathrm{GHz}$ beam is normally colder than the +2 degree $89 \mathrm{GHz}$ beam.

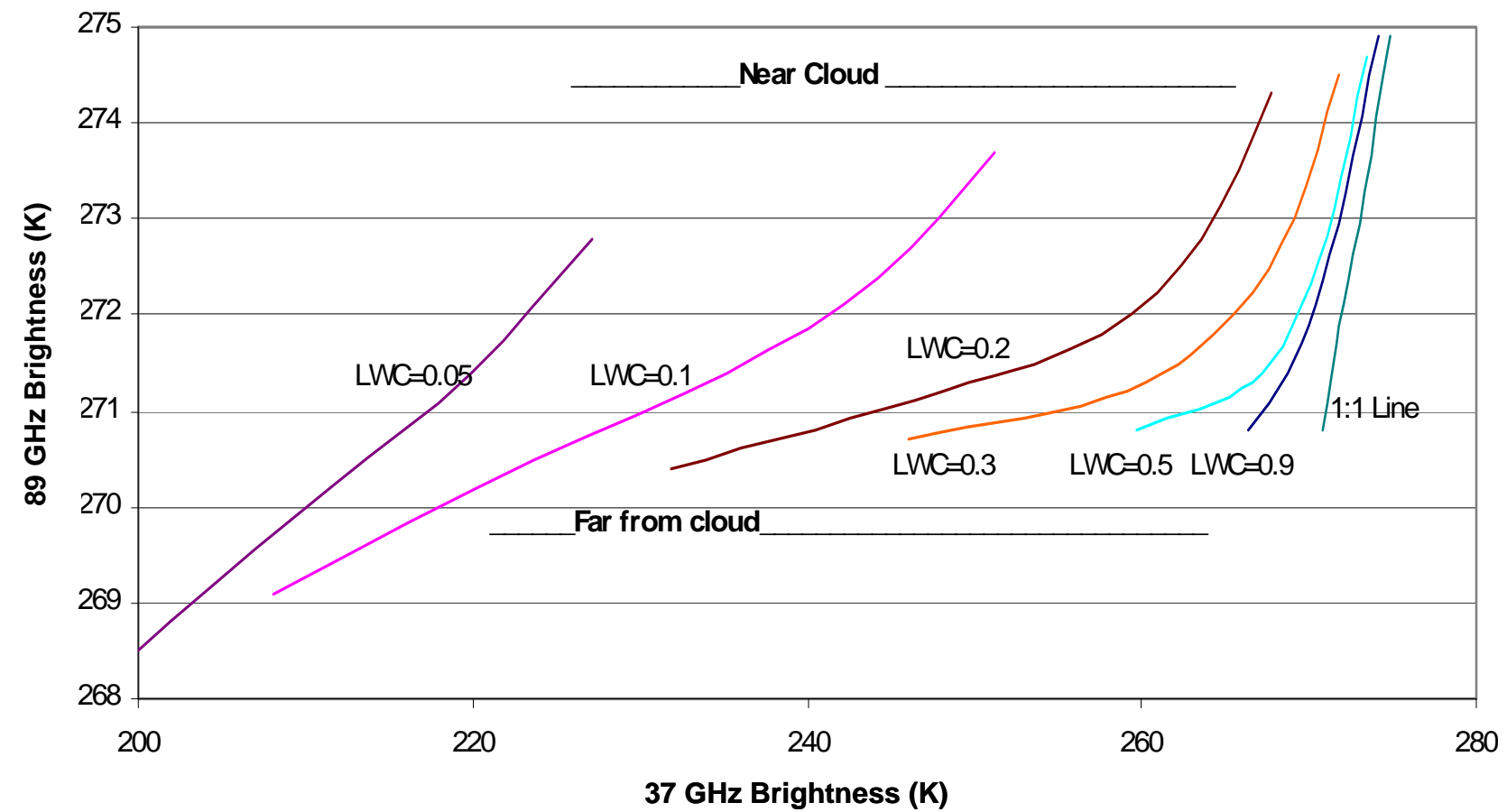

Fig. 2. Joint brightness temperatures $(37 \mathrm{GHz}, 89 \mathrm{GHz})$ in the $+2^{\circ}$ beam as the sensor approaches clouds of differing cloud liquid water content. Dual frequencies permit a dual estimate of attenuation, permitting separation of the effects of distance and water content.

Normally, as an aircraft approaches a cloud, the +2 degree beam and the horizontal beam converge in brightness temperature, the rate of convergence depending upon distance from the cloud, cloud height above the flight altitude, temperature changes with altitude, and cloud LWC. As the aircraft gets closer to the cloud the +2 degree viewing sensors start to intercept the cloud, and the in-cloud path lengths intercepted by the +2 degree viewing sensors increase to a point-when the beams 'see' through the cloud and out the back. During the approach, the brightness temperature of the +2 degree beams approach the brightness temperatures of the horizontal looking sensors.

An estimate of LWC magnitude is obtained by comparing the brightness temperatures of the 37- and 89-GHz beams in the +2 degree orientation. Since the $37-\mathrm{GHz}$ beam normally penetrates farther into cloud than the $89-\mathrm{GHz}$ beam, the 37-GHz brightness temperature will be colder than the 89-GHz brightness temperature. If there is little cloud liquid water the $37 \mathrm{GHz}$ detector 'sees' colder regions of the cloud or even the colder atmosphere above the cloud. As Cloud Liquid Water Content (CLWC) increases, the +2 degree $89-\mathrm{GHz}$ and 37-GHz brightness temperatures converge as the cloud transmissivity decreases. For the +2 degree view direction, Figure 2 shows relationships between $37 \mathrm{GHz}$ and $89 \mathrm{GHz}$ brightness temperatures and CLWC. For example, a CLWC of $0.05 \mathrm{gm}^{-3}$ results in a 37 and $89 \mathrm{GHz}$ brightness temperatures of 220 degrees $\mathrm{K}$ and 272 degrees K respectively, , while a LWC of $0.9 \mathrm{gm}^{-3}$ results in a 37 $\mathrm{GHz}$ and $89 \mathrm{GHz}$ brightness temperature of about 270 degrees $\mathrm{K}$ and 272 degrees K, respectively. Savage et al. ${ }^{3}$ speculated that the presence of drizzle-size drops can be detected by sensing polarized radiation scattered by large drops, hypothesizing that polarization results from drizzle drop scattering of polarized radiation from Earth surfaces, and shape distortion of the largest drops. 


\section{SIMULATION}

Concepts of operation were evaluated using the RADTRAN model that predicts brightness temperature and attenuation for ground based and space-based microwave radiometers along vertical and slant paths ${ }^{7}$. The brightness temperature for a downward looking microwave sensor depends on the surface emitted radiance attenuated by the atmosphere between the ground and the sensor, and the atmosphere emitted radiance between the surface and the sensor. For an upward looking sensor the radiance associated with the ground is replaced by a constant brightness temperature representing cold space attenuated by the atmosphere between the sensor and space plus the atmospheric contribution. RADTRAN calculates the attenuation, transmittance, and brightness temperatures based on the radiative transfer equation for thermal emission at microwave frequencies, and considers scattering by hydrometeors, multiple scattering, and emission and scattering by natural surfaces (grasses, ocean, etc).

RADTRAN has six predefined atmospheric profiles; tropical, mid-latitude summer and winter, sub-artic summer and winter, U.S 1962 standard atmosphere, plus a user defined atmospheric can be entered. Clear sky atmosphere absorption is due primarily to water vapor and oxygen ${ }^{7}$. In the microwave region the Rayleigh approximation is used to compute the attenuation due to clouds; a capability to model partial or fully glaciated clouds is not available. Though precipitation can be either in a liquid or solid state, the model allows the cloud volume extinction cross-section to be defined in terms of the mass of the CLWC.

RADTRAN was originally a plane parallel model and therefore the model did not handle the situation of a radiometer placed in the nose of an aircraft looking horizontally forward to detect potential icing conditions ahead. ERDC/CRREL, Sensor Concepts and Applications, and NASA, in conjunction with the Air Force Research Laboratory (AFRL), sponsored the modification of RADTRAN to handle the aircraft scenario by using a concentric layered atmosphere and providing a 'fly through' capability ${ }^{8}$. For a sensor that is not viewing directly upward or downward the concentric shell approach more faithfully approximates the path through each layer. Since a multifrequency, multi-view MMW radiometer can potentially provide information that can be used to define an icing potential metric, it is now possible to simulate an aircraft-mounted multi-frequency, multi-view sensor. Also, a Graphic User Interface (GUI) now makes it considerably easier to generate the input information required by the model.

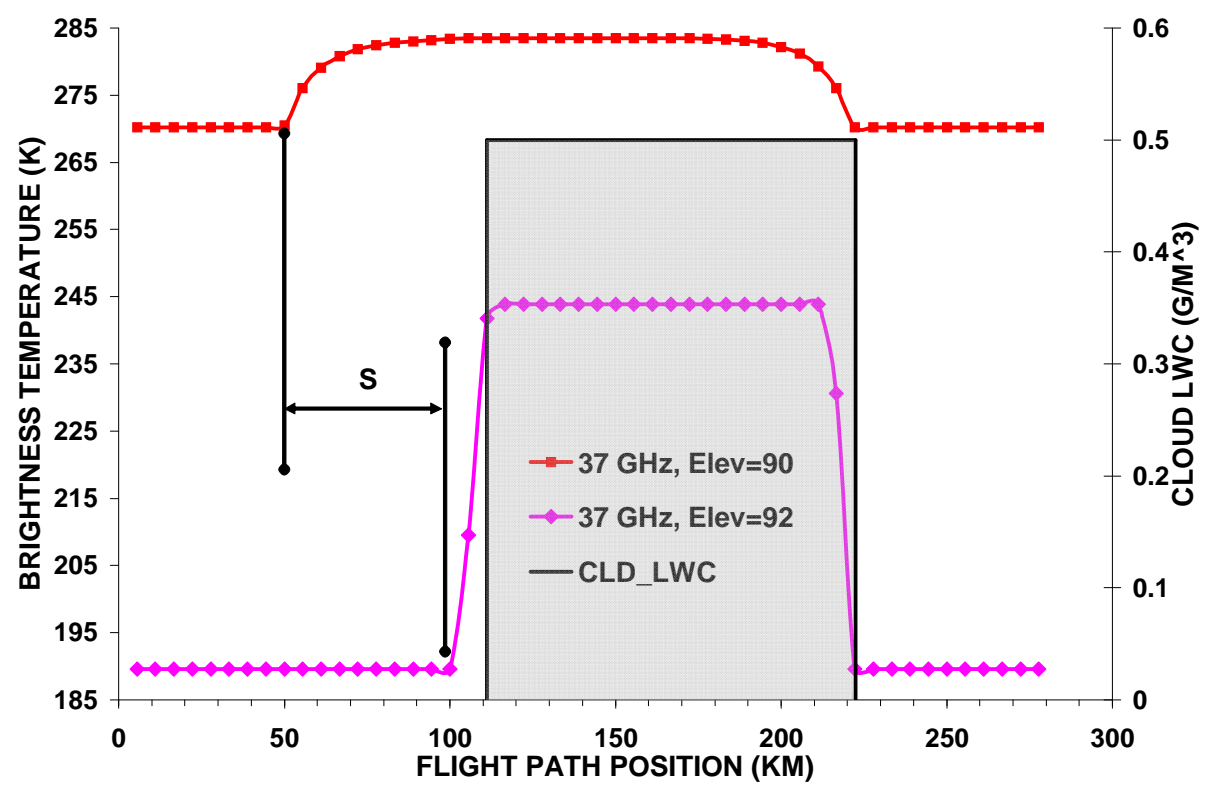

Fig. 3. $35 \mathrm{GHz}$ brightness temperatures associated with 90 degree (horizontal) and 92 degree (2 degrees above the horizontal view) view directions for a radiometer on an aircraft approaching a single cloud. 


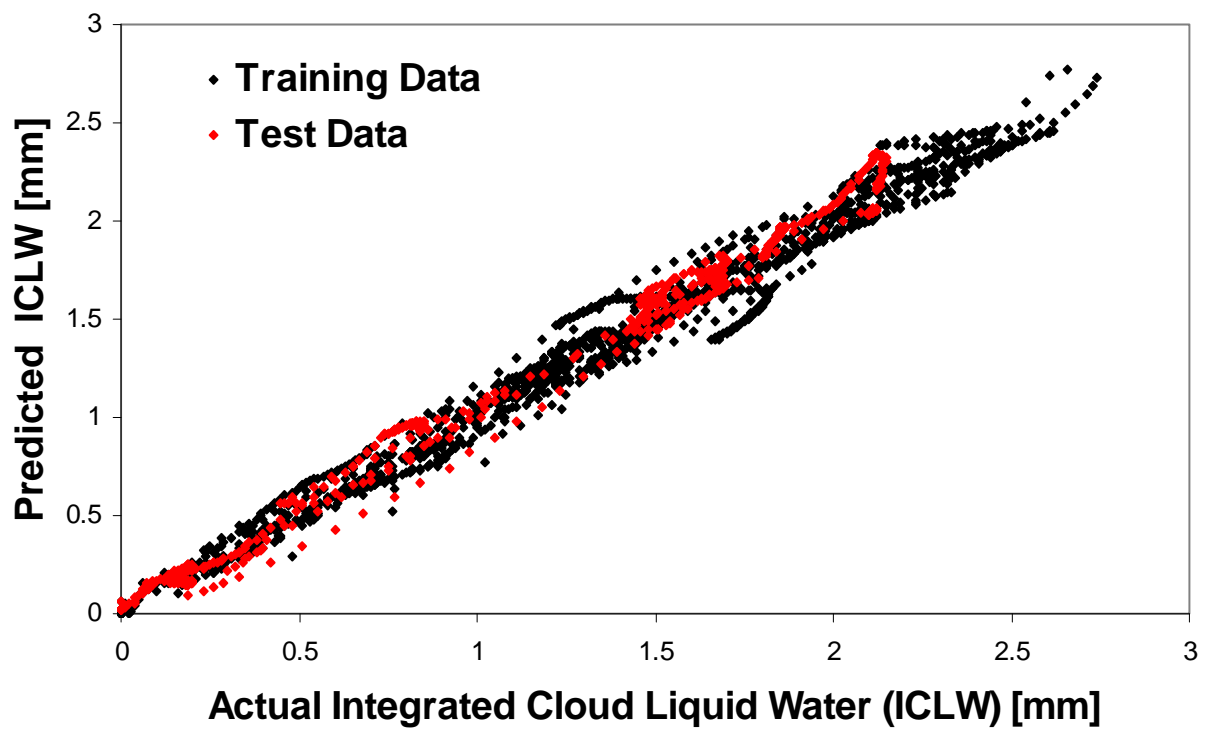

Fig. 4. Actual integrated liquid water content versus integrated cloud liquid water content predicted using two frequencies (37 and $89 \mathrm{GHz}$ ) along the slant path and one frequency along the horizontal path as the input vector.

The modified Savage et al. ${ }^{3}$ Microwave Icing Avoidance System model was used to predict the MMW brightness temperatures by solving the MMW brightness temperature equation for the desired MMW frequency and the spatial distribution of CLWC, water vapor and temperature. The model output consists of the Integrated Cloud Liquid Water (ICLW) and brightness temperature as a function of frequency and view direction. The net was trained using approximately 10,000 cases and evaluated using independent cloud scenarios. Figure 4 shows the relationship between measured and predicted ICLW using the neural network model.

\section{HARDWARE}

The MMW brightness temperature of most earth materials is typically different in the vertical and the horizontal, with the vertical brightness temperature often warmer than the horizontal except for vegetation. Therefore, Savage et al. ${ }^{3}$ hypothesized that surface emitted MMW energy scattered by drizzle and raindrops will also be polarized and the apparent cloud temperatures for the horizontal and vertical polarization will differ if clouds contain drizzle and/or rain drops. This is because the volume scattering efficiency of large drops is several orders of magnitude greater than cloud size drops. In addition, large rain drops that are non-spherical emit or scatter MMW radiation differently than spherical drops resulting, again, in different horizontal and vertical brightness temperatures. These differences in brightness temperature and polarization are clues that large drops are present with their uniquely hazardous icing conditions when the drop temperatures are below freezing.

Hardware development was intended to satisfy many of the requirements identified by Savage et al. ${ }^{3}$. Radiometers must operate at or near 36 to 37 and 86 to $92 \mathrm{GHz}$, and must measure the polarization to detect Supercooled Large Drops (SLD). ERDC-CRREL sponsored development of two polarimeters by Waveband, Inc. (now Waveband Business Unit of Sierra Nevada Corporation) through the Army Small Business Innovation Research (SBIR) program, one operating at $35 \mathrm{GHz}$, and the second at $94 \mathrm{GHz}$. The Direct Detection Polarimetric Radiometers (DDPR) employ a Spinning Phase Retarder (SPR). During each rotation of the SPR, the output signal of the SPR varies in amplitude and phase. All polarimetric information is gathered from the processing of the rapidly varying signal. The small polarimeters, weighing less than $20 \mathrm{~kg}$ each, using a single antenna and a single amplifier for each frequency; directly measure the second, third and fourth Stokes parameters and derive a pseudo first Stokes parameter from the other three that represents the intensity of the polarization. The system also provides a DC output that may be used to obtain the brightness temperature (the first Stokes parameter) that represents the total intensity of the radiometric signal. 


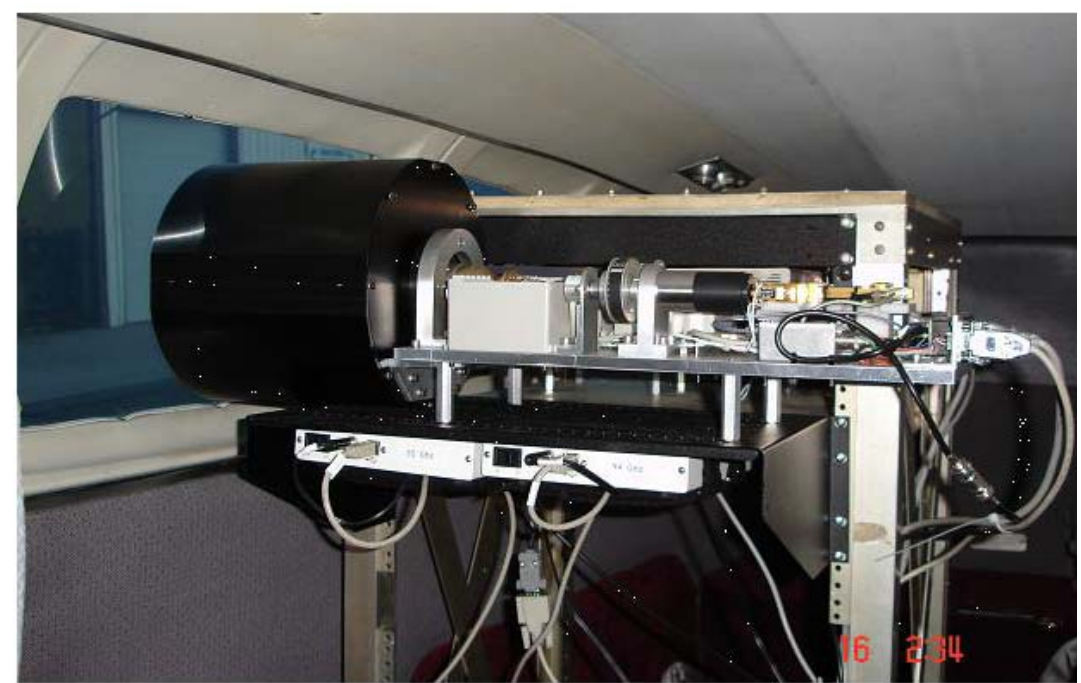

Fig. 5. $35 \mathrm{GHz}$ polarimeter aimed out the right side of the aircraft and forward of the $94 \mathrm{GHz}$ polarimeter (not visible behind the $35 \mathrm{GHz}$ polarimeter) viewing through the same window.

\subsection{Polarimeter flight tests}

DDPR flight tests were conducted by Sierra Nevada in November, 2006, with CRREL's participation (the senior author) in December 2006. The goal of the test was to determine qualitatively and, if possible, quantitatively how the instruments responded to a variety of targets including clear sky, warm $\left(>0^{\circ} \mathrm{C}\right)$ and cold $\left(<0^{\circ} \mathrm{C}\right)$ clouds, water, soil, and built-up areas. The polarimeters were placed to view outside the right side of a Cessna 404 through a side window (Fig. 5). A video camera forward of the polarimeters approximated the view direction of the polarimeters.

Here, a brief assessment of DDPR response during the flight tests is provided. The aircraft was not icing certified so it could not traverse clouds where icing might be expected. In addition, no cloud microphysics instruments were placed on the aircraft. The only atmospheric measurement available was outside air temperature. Flight guidance to desired cloud conditions was provided by a dedicated forecaster with expertise in locating icing conditions.

Though more conditions were recorded, we show the DDPR response during near clear sky conditions, potential supercooled or glaciated clouds inferred from the level of the cloud relative to the aircraft and the outside temperature as recorded at the aircraft, warm clouds, and ground features. Sky features were typically acquired during left turns where the aircraft banked up to 30 degrees. Since polarimeter angle of view was 3 degrees for $35 \mathrm{GHz}$ and $94 \mathrm{GHz}$, a 30 degree bank, or even less, will not include ground features. Signatures of ground features were taken in right turns of generally 30 degrees to 45 degrees bank. Some signatures were also acquired during straight and level flight to allow signature to be acquired from sky and intermittent ground features such as mountains when at lower altitude. What the sensor 'sees' is a function of altitude and aircraft roll.

Q, U, and V Stokes parameters are illustrated for a variety of targets. Q is the difference between horizontal and vertical polarization, $\mathrm{U}$ is the difference between +45 degree and -45 degree polarization, and $\mathrm{V}$ is difference of left and right hand circular polarization. The figures below present the signal strength associated with $Q, U$, and $V$ and, in some cases, a normalized value of $\mathrm{Q}, \mathrm{U}$, and $\mathrm{V}$ obtained by dividing the value of $\mathrm{Q}, \mathrm{U}$, or $\mathrm{V}$ by the computed value of I derived from $\mathrm{Q}, \mathrm{U}$, and $\mathrm{V}$. The range of the normalized $\mathrm{Q}, \mathrm{U}$, and $\mathrm{V}$ values is from +1 to -1 and represents the fraction of the polarization attributed to that Stokes parameter (Q, U, V). However, a value of one for any of the three Stokes parameters $(\mathrm{Q}, \mathrm{U}, \mathrm{V})$ does not mean the radiation is fully polarized. That is, the normalized values of Q, $\mathrm{U}$, and $\mathrm{V}$ represent the fraction of the polarization component of radiation (the radiation may not be fully polarized) attributed to that parameter. 


\subsubsection{Clear sky}

Figure 6 shows, for the $94 \mathrm{GHz}$ DDPR, signals that fall, we believe, within the polarimeter's instrument noise. Laboratory 94 and $35 \mathrm{GHz}$ measurements without a polarization source present exhibit similar values. In general, a clear sky should show no polarization,. The clear sky signal strengths for $35 \mathrm{GHz}$, obtained from a different flight, are similar to the $94 \mathrm{GHz}$ values as indicated in the table in figure 6.

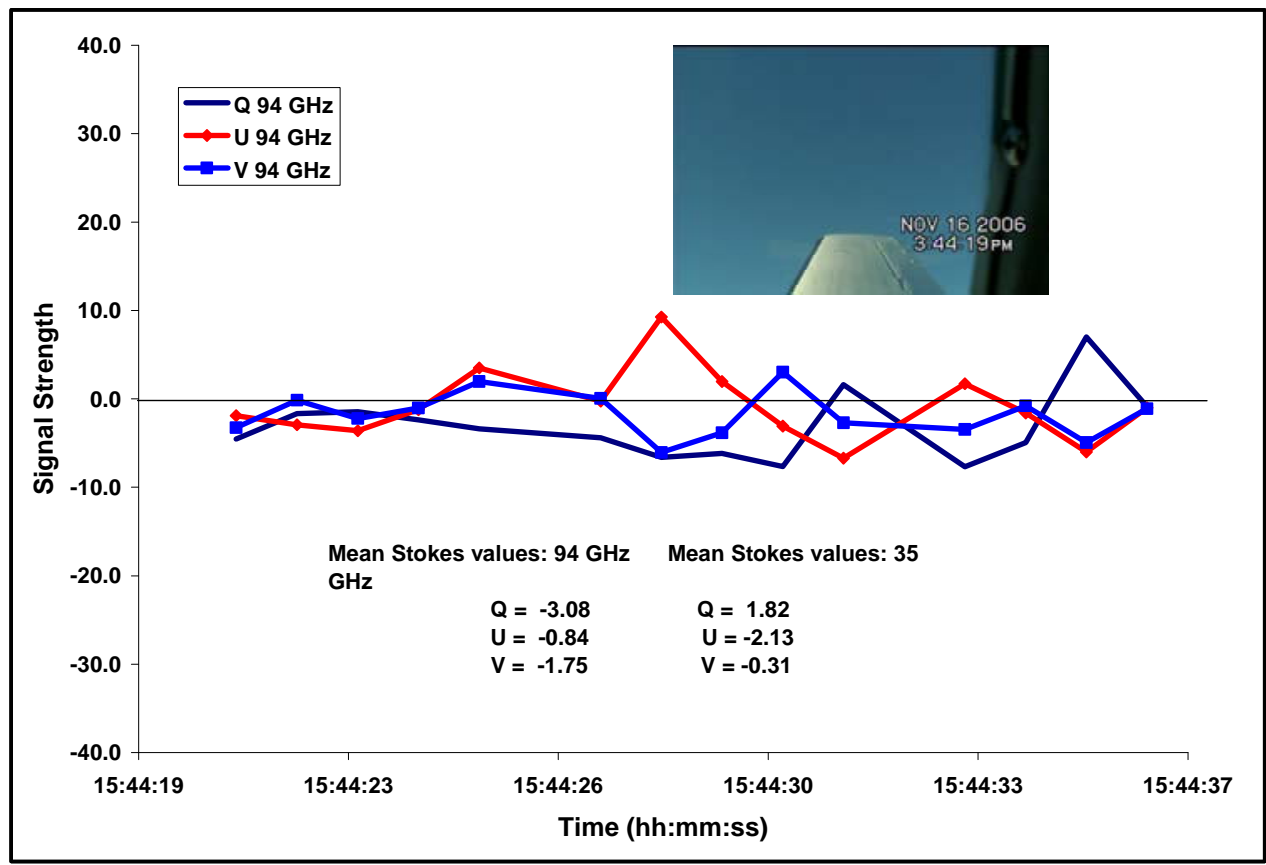

Fig. 6. $94 \mathrm{GHz}$ clear sky polarization with approximate DDPR view and summary of values from a separate $35 \mathrm{GHz}$ flight

\subsubsection{Clouds}

We generally looked up into clouds from near their base, though in same cases the aircraft was hundreds of meters below cloud base. Both examples illustrated below are from immediately below cloud base.

The first example is at an air temperature of -18 degrees $\mathrm{C}$ outside the aircraft. If a normal lapse rate is assumed, then the clouds observed above the aircraft are certainly below freezing, and are likely mixed phase or fully glaciated at a temperature of -18 degrees $C$ or colder.

Similarly to the clear sky plot in Figure 6, Figure 7 shows DDPR signal responses, in this case for the $35 \mathrm{GHz}$ and the $94 \mathrm{GHz}$ instruments, to be of small amplitude and within the probable instrument noise floor of the polarimeters. This suggests that the cloud may have been comprised of supercooled small (cloud) drops only with no ice, or it suggests that the instruments are insufficiently sensitive to detect any ice that may have been present. The presence of ice within the cloud could not be verified because the aircraft was not equipped for cloud microphysics measurements. We are currently investigating the sensitivity of the instruments.

Figure 8 shows a case where the aircraft is again at a 30 degree bank looking up into the cloud base. The air temperature at the aircraft was +5 degrees $C$ suggesting that the cloud base may also be warmer than freezing. However, if the cloud is deep and the lapse rate was normal, then part of the cloud may have been mixed phase, or could have been fully glaciated. If this was a water cloud consisting of mainly cloud drops we would anticipate $\mathrm{Q}=\mathrm{U}=\mathrm{V} \sim 0.0$. Unfortunately, there was no onboard instrumentation for obtaining cloud micro-physical properties. 
The virtual fly-through capability in RADTRAN operates as follows. The user specifies the cloud and atmospheric conditions, the frequencies and view directions, the start and end point of the flight path, and the altitude of the flight path. At designated points along the flight path the cloud atmospheric conditions are determined. RADTRAN then computes the brightness temperatures, attenuation, and transmission for each frequency and view direction at 250-m intervals along the flight path.

Fig. 3 is an example of a flight with $37 \mathrm{GHz}$ radiometers with 90 and 92 degree viewing directions used to compute both the distance to a cloud ahead of the aircraft and the cloud top altitude. A single cloud (gray in Fig. 3) with a CLWC of $0.5 \mathrm{~g} / \mathrm{m}^{3}$ and a cloud base and top altitude of $0.3 \mathrm{~km}$, and $1.0 \mathrm{~km}$ respectively extends along the flight path from $111 \mathrm{~km}$ to $222 \mathrm{~km}$. The aircraft flight altitude is constant at $0.7 \mathrm{~km}$. Initially, the cloud is below the horizon even for the 90 degree viewing direction because of Earth-atmosphere curvature. When the aircraft is approximately $50 \mathrm{~km}$ from the leading edge of the cloud, the $37 \mathrm{GHz}$ brightness temperature for the 90 degree view direction jumps almost 55 degrees Kelvin, indicating the radiometer is 'seeing' the cloud. At approximately $10 \mathrm{~km}$ from the cloud, the $37 \mathrm{GHz}$ brightness temperature at the 92 degree viewing direction jumps 16 degrees Kelvin. From the aircraft altitude and the arc distance $\mathrm{S}$ between when the 90 degree viewing sensor first 'sees' the cloud and the 92 degree viewing sensor detects the cloud it is possible to compute the cloud top altitude and the distance to the cloud from the position when the 92 degree viewing sensor first detects the cloud. From this procedure, the calculated cloud top is $0.96 \mathrm{~km}$ and the distance to the cloud is $9.2 \mathrm{~km}$, while the actual values are 1.0 and $10 \mathrm{~km}$, respectively. To explore the use of RADTRAN for modeling multi-frequency, multi-view radiometer systems that could be used to derive cloud LWC from the MMW brightness temperatures, a variety of cloud scenarios have been explored, including cloud masses with multiple liquid water contents ${ }^{8}$.

\section{CLOUD LIQUID WATER CONTENT INVERSION}

A successful MMW radiometer-based system must provide indications of cloud water content from cloud brightness temperature. There is no analytical inversion technique that can predict icing potential from brightness temperature measurements from a horizontally pointing MMW radiometer. As shown by RADTRAN, it is fairly simple to solve the forward problem of predicting the MMW brightness temperature; it is the inversion of the brightness temperature to obtain the cloud microphysical parameters critical to predicting icing that is difficult.

Neural Network (NN) models are well suited for situations where the forward problem is relatively easy to solve but the inverse problem is fairly difficult ${ }^{9}$. Though neural nets may solve the radiometer liquid water inversion problem, there is an art to training neural nets. If over trained, the net memorizes the path through the net, if under trained the net may key on a local solution rather than the global solution. Despite these problems, the use of neural nets to invert MMW brightness temperature to obtain cloud microphysical parameters is promising.

Massie et al. ${ }^{9}$ developed a NN model to predict liquid water content for the ERDC-CRREL system. The neural net was trained with input vectors of Integrated cloud Liquid Water Content (ILWC) for specified spatial distributions of cloud LWC, water vapor, and temperature as a function of MMW frequency, and sensor view direction. The output vectors are the MMW brightness temperatures for each frequency and view direction. The spatial distribution of cloud LWC was specified using aircraft data collected by NASA in supercooled (icing) clouds over the Great Lakes and Ohio including LWC, drop size distribution and outside air temperature along the flight path at a sampling resolution of approximately 90 meters.

Five independent data collection periods were used to define the envelope of atmospheric conditions conducive to icing and to develop the input and output vectors for training the neural net. For each aircraft data set, the average vertical LWC profile and CLWC variations as a function of the height above cloud base were determined. The horizontal distribution of CLWC was specified by defining regions (clusters) where the variations in the CLWC were random. For each region, an average CLWC was used to reduce computational burden to a manageable level. The coherence lengths associated with the clusters were obtained using a two-point correlation function. The Air Force Geophysics Laboratory standard mid-latitude winter atmospheric profile was used to specify the distribution of water vapor and temperature. 


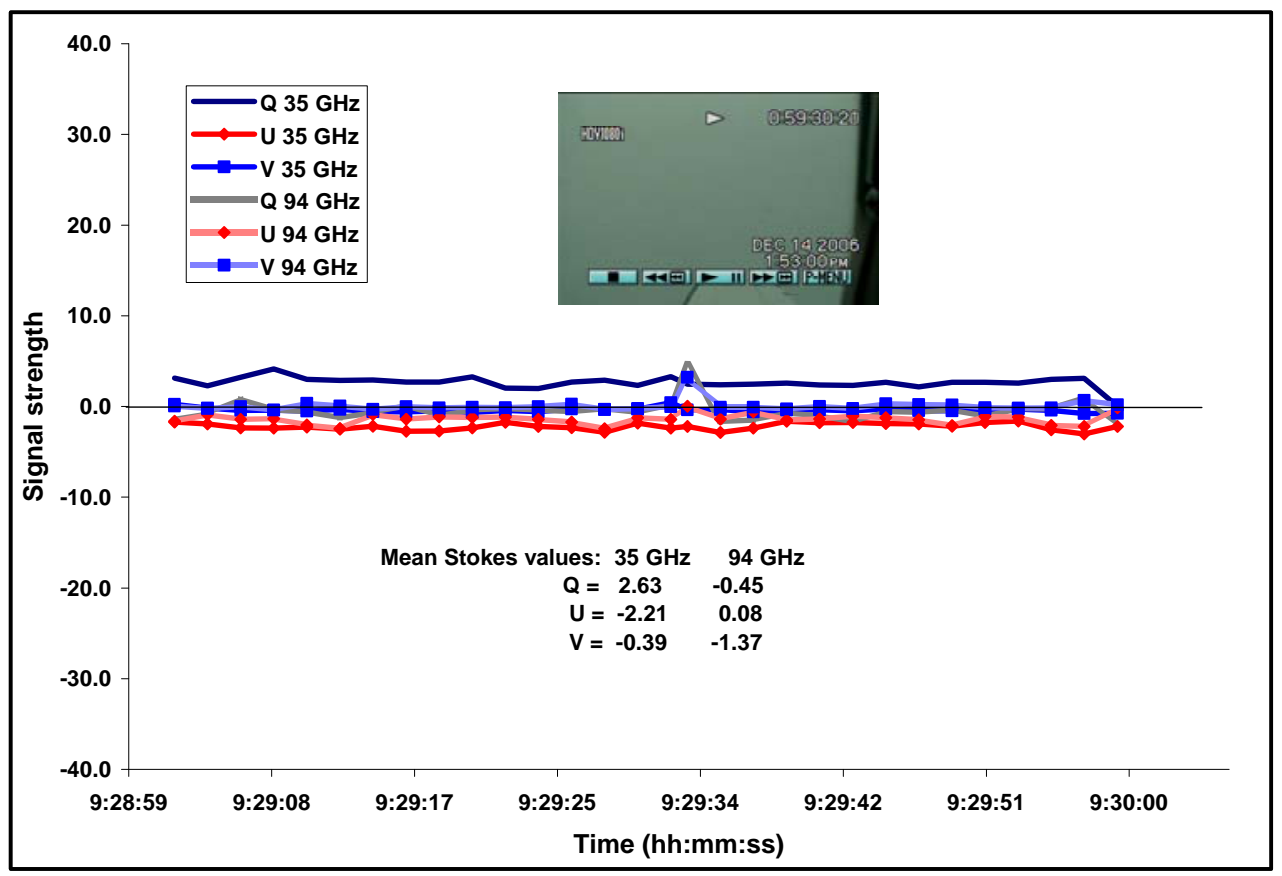

Fig. 7. Plots of $35 \mathrm{GHz}$ and $94 \mathrm{GHz}$ DDPR signal strengths for a -18 degree C supercooled cloud with the approximate polarimeter view.

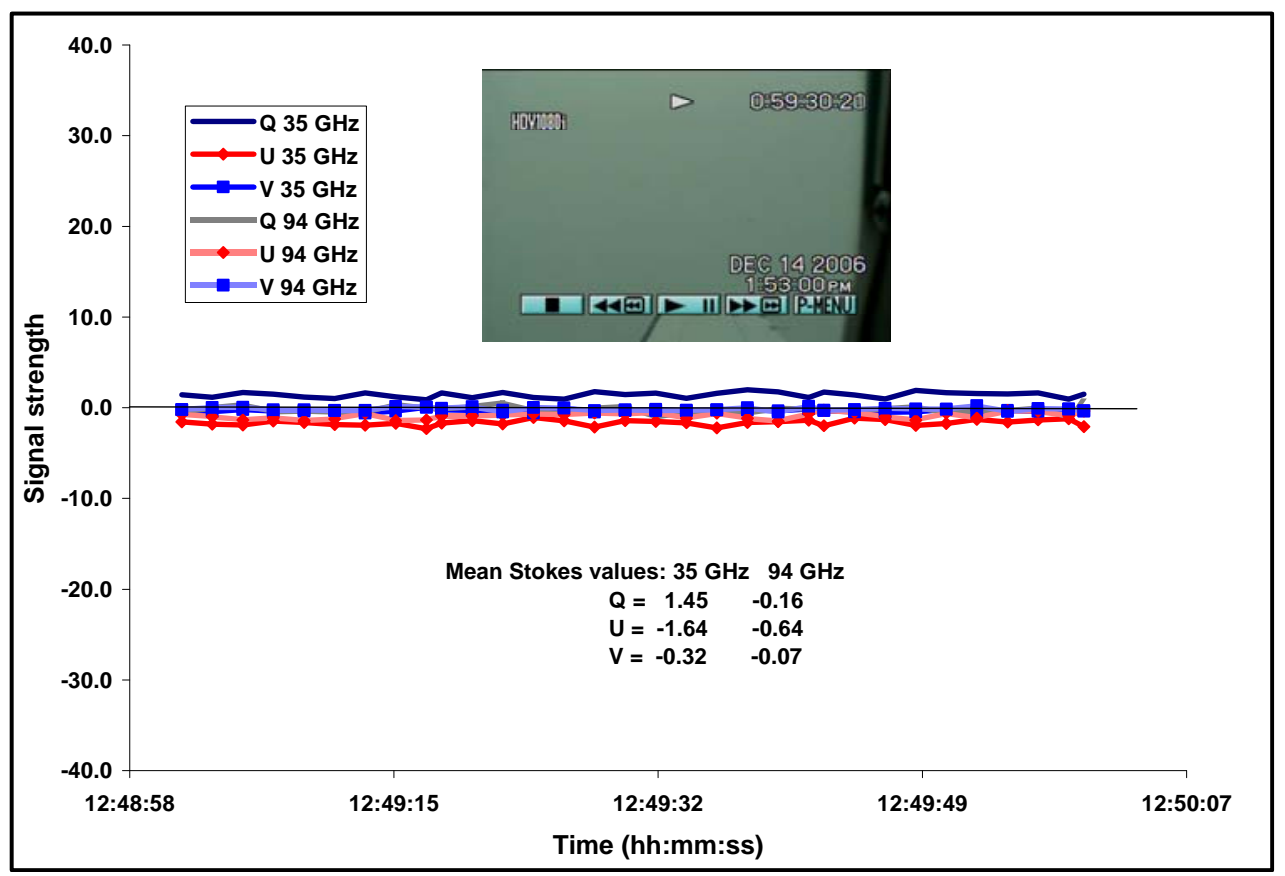

Fig. 8. Plot of $35 \mathrm{GHz}$ and $95 \mathrm{GHz}$ DDPR signal strengths for a warm cloud (+5 degree C) with the approximate polarimeter view. 

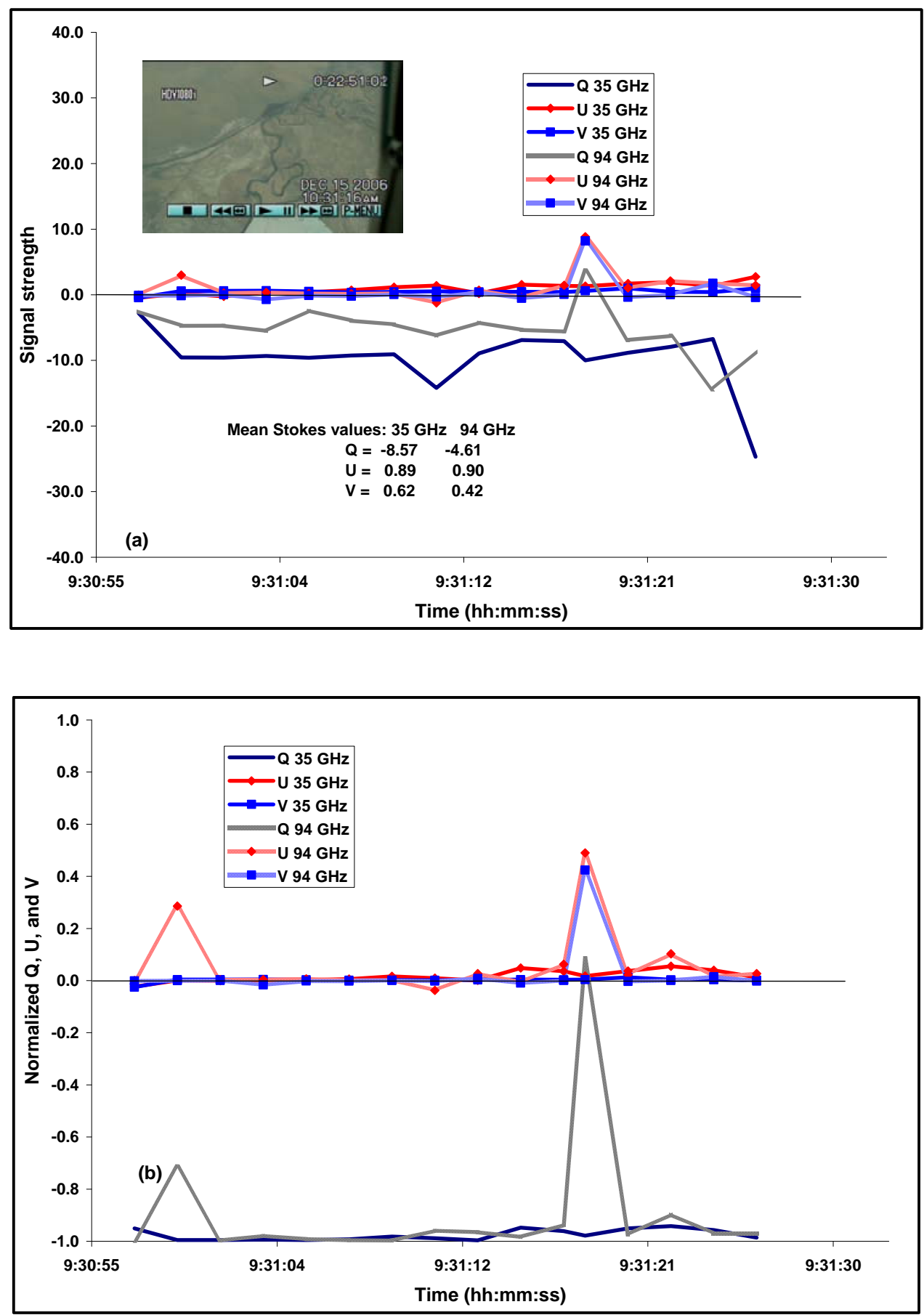

Fig. 9. a) Plot of $35 \mathrm{GHz}$ and $94 \mathrm{GHz}$ signal strength for a terrestrial area consisting of a creek and flood plain. b) normalized $\mathrm{Q}, \mathrm{U}$, and $\mathrm{V}$ values corresponding to the values in (a). 

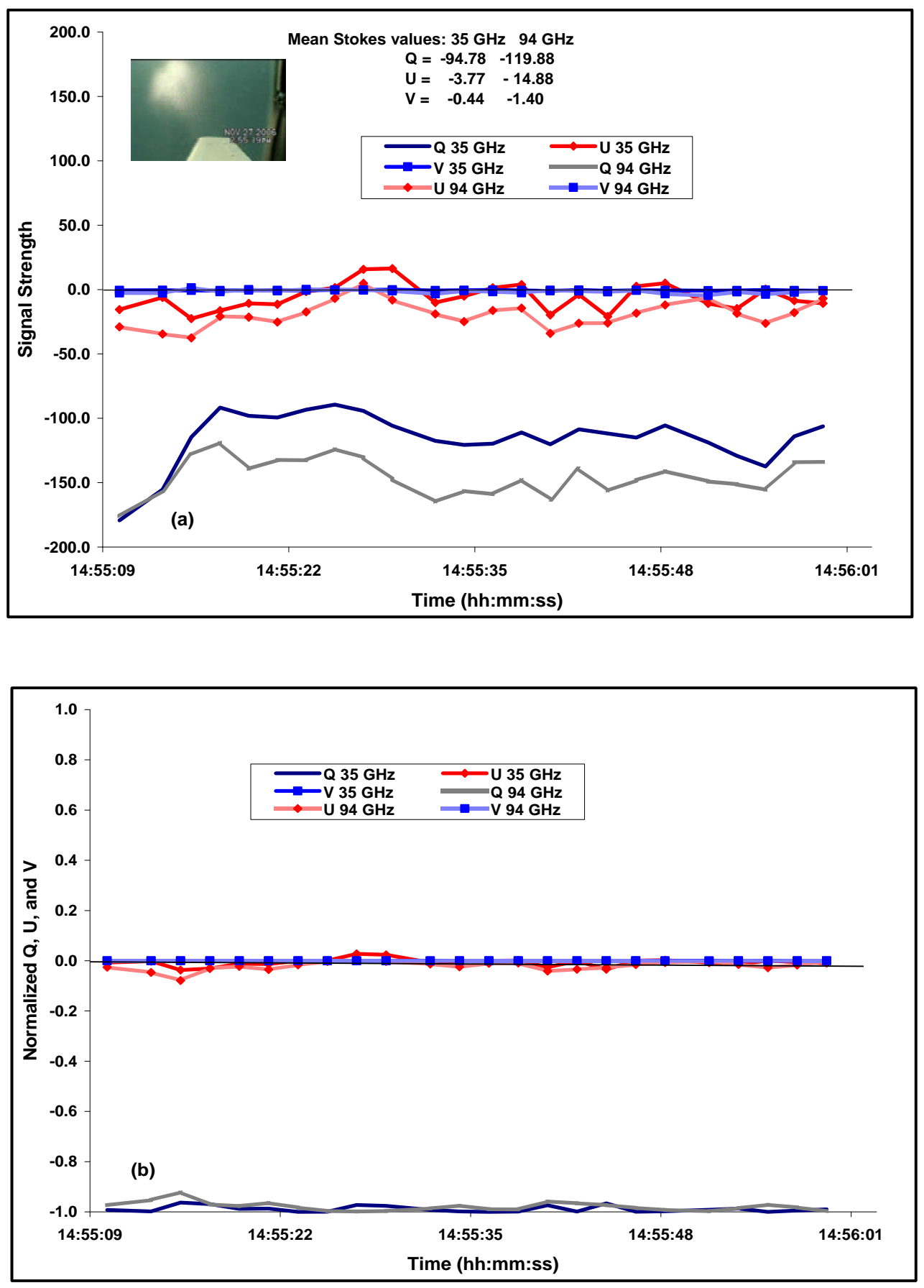

Fig. 10. a) Plot of $35 \mathrm{GHz}$ and $94 \mathrm{GHz}$ signal strength for Pyramid Lake during a steep turn. b) normalized Q, U, and V values corresponding to the values in (a). 

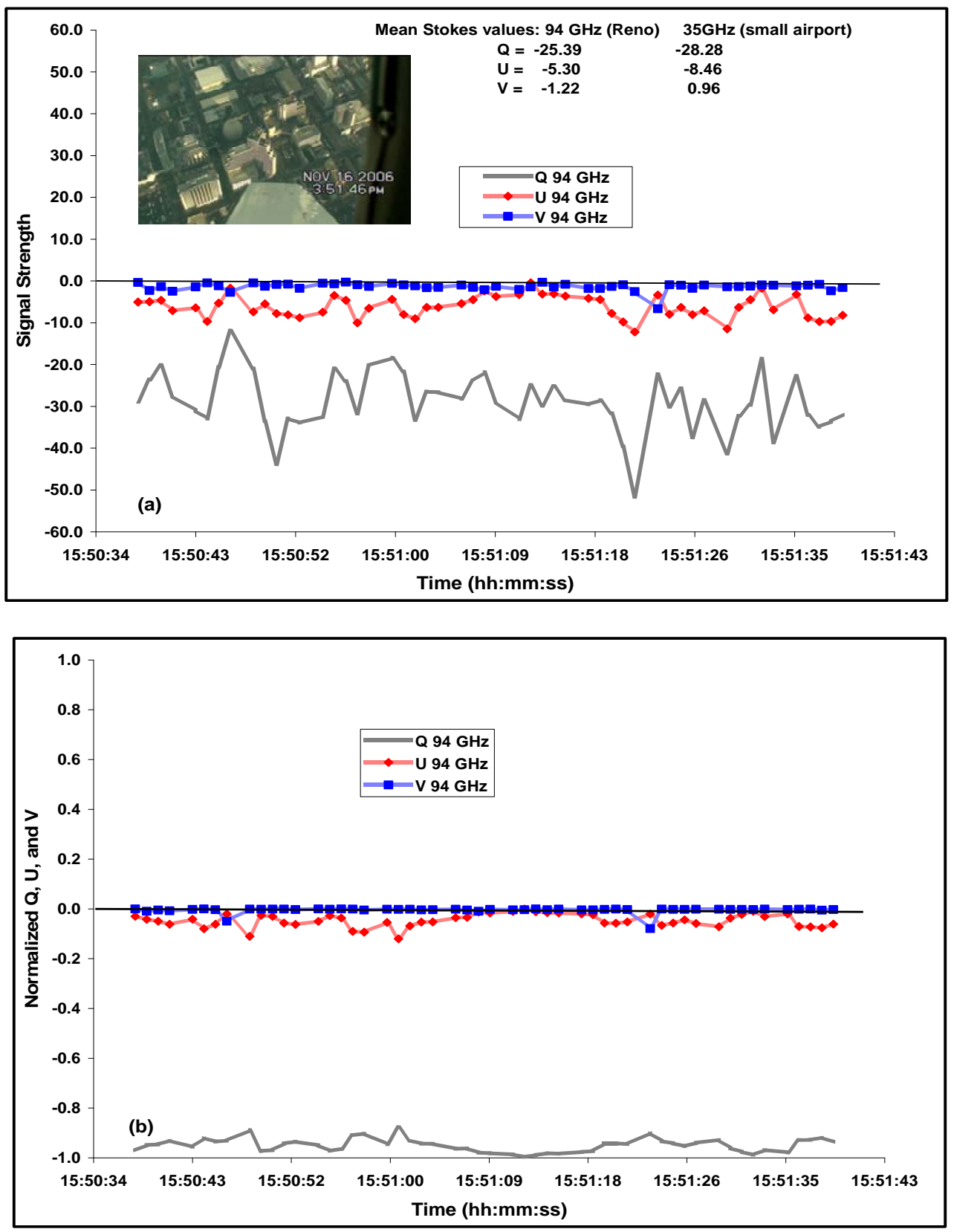

Fig. 11. a) Plot of $94 \mathrm{GHz}$ signal strength for Reno b) normalized Q, U, and V values corresponding to the values in (a)

\subsubsection{Terrestrial features}

Terrestrial features tend to emit partially polarized radiation. The signal strength of $Q$ in Figure 9a is greater than the values observed for clear sky and warm and cold clouds. In Figure 9b nearly all polarization is accounted for by Q at both $35 \mathrm{GHz}$ and $94 \mathrm{GHz}$. Other terrestrial features showed a similar response to the creek and flood plain view in Figure 9. While the value of $\mathrm{Q}$ is approximately 1.0 in figure $9 \mathrm{~b}$ it is important to note that this does not imply the surface emitted and reflected 34 and $95 \mathrm{GHz}$ radiation is fully polarized. This number represents the fraction of the polarization attributed to Q, U, or V. For the example of water given in Figure 10 most of the polarization is associated 
with Q and only a small fraction (less than 0.2 ) is associated with U. Figure 11 for a built-up area exhibits similar normalized Q, U, and V values. Due to instrument problems, $35 \mathrm{GHz}$ DDPR information is not available for the flights over Reno. However, we collected $35 \mathrm{GHz}$ information on a different day over a local airport consisting of a runway and several buildings including hangers. The Table insert in Figure 11 represents the average value of the $35 \mathrm{GHz}$ signal strength. On the average, Q represents $93 \%$ of the $35 \mathrm{GHz}$ polarization strength for this flight, while $\mathrm{U}$ accounts for $6.7 \%$ of the polarization strength. For the flight over Reno Q represents $95 \%$ of the $94 \mathrm{GHz}$ polarization strength, while $\mathrm{U}$ accounts for $5 \%$ of the polarization strength. The Q signal strengths are greatest for the water and smallest for the creek and flood plain, while the built-up area values fall in-between. For all the examples the $\mathrm{V}$ values are at the instrument noise level and only the water and built-up examples have U values above the noise floor. In general, the values of Q should be negative for terrain and water surfaces. In terms of signal strength, Q should have the greatest values for a water surface and smaller values for terrain.

\section{DISCUSSION AND CONCLUSIONS}

All basic elements necessary to assess the capability of microwave radiometers for detecting icing conditions from aircraft in-flight have been developed; concept of operation, simulation of operational configuration, inversion of brightness temperature to integrated cloud liquid water content, and instrumentation. RADTRAN simulations show that multiple frequencies and multiple fields of view do provide unique brightness temperatures that can be used to detect icing conditions, and even to estimate distance to clouds.

The neural-network-based inversion technique demonstrates that integrated cloud water can be retrieved from brightness temperatures. Though cloud parameters are specified with explicit cloud liquid water contents for RADTRAN, microwave radiometry provides only the integrated liquid water over a path length limited by the transmissivity of the cloud. Integrated values are useful, however, because ice formation on airfoils is an integration of the variable supercooled water content intercepted by the aircraft.

Initial flight tests of the $35 \mathrm{GHz}$ and $94 \mathrm{GHz}$ polarimeters indicates that polarization is being measured and that they are sufficiently sensitive to detect variable ground conditions. However, more analysis and testing will be necessary to determine their utility. In addition, though the polarimeters provide the magnitude of three of the four Stokes parameters, Q, U, and V, they do not provide a direct brightness temperature measurement. We are exploring whether the DC component available from the instruments may be related to and used similarly to brightness temperature for estimating integrated cloud water content.

Should the polarimeters prove to provide consistent polarimetry, prove sufficiently sensitive, and if the DC signal can be related to brightness temperature, then the instruments may make test flights on NASA Glenn Research Center's Twin Otter research aircraft. That aircraft also measures cloud properties such as LWC, particle size, and temperature, allowing quantitative verification of polarimeter measurements. We will continue assessment of the flight measurements, and conduct ground tests of the polarimeters to develop a better understanding of their capability. 


\section{REFERENCES}

Moran, M.P., and Singer, M.J., “CIP and FIP: A Pilot’s Perspective,” The Front (4), 1-2 (2005).

Grody, N., "Remote Sensing from Satellites Using Microwave Radiometry," Microwave radiometry short course, American Meteorological Society Annual Meeting, Long Beach, California (1997).

Savage, R., Lines, R., Cole, J., and Koenig, G., "A passive microwave icing avoidance system (MIAS)., Paper P12.9, Proceedings of the American Meteorological Society 8th Conference on Aviation, Range and Aerospace Meteorology, 12-15 January, Dallas, Texas, 457-461 (1999).

Reehorst, A., Politovich, M., Zednik, S., Isaac, G., and Cober, S., [Progress in the Development of Practical Remote Detection of Icing Conditions], NASA/TM-2006-214242, 16 (2006).

Ryerson, C., Politovich, M., Reehorst, A., and Koenig, G., "Mt. Washington Icing Sensors Project (MWISP) Results," Proceedings of the American Meteorological Society 10th Conference on Aviation, Range, and Aerospace Meteorology, 13-16 May, Portland, OR, 228-231 (2002).

Ryerson, C., [Remote Sensing of In-flight Icing Conditions: Operational, Meteorological, and Technological Considerations], ERDC/CRREL M-00-1, NASA/CR-2000-209938, 75 (2000).

Falcone, V.J., Abreu, L.W., and Shettle, E.P., [Atmospheric Attenuation of Millimeter and Submillimeter Waves: Models and Computer Code], AFGL-TR-79-0253, Air Force Geophysics Laboratory, Hanscom AFB, Bedford, MA, NTIS ADA084485, 76 (1979).

Koenig, G, Ryerson, C., and Nagle, J., 2004 "Using RADTRAN to Simulate an Aircraft Microwave Radiometer to Detect Icing Potential,” AIAA-2004-0234, American Institute of Aeronautics and Astronautics 41st Aerospace Sciences Meeting and Exhibit, 6-9 January, Reno, 11 (2004).

Massie, D., Koenig, G., and Ryerson, C., "The Use of Neural Nets to Invert Passive Millimeter Wave Brightness Temperatures to Predict Aircraft Icing Potential,” 23rd Army Science Conference, Environmental and Geosciences, 2-5 December 2002, Orlando, 2 (2003). 


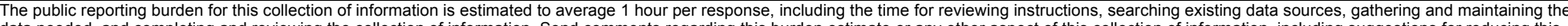

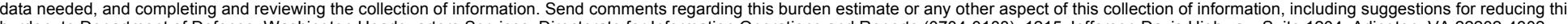

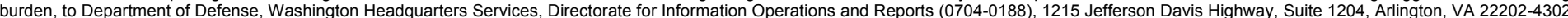

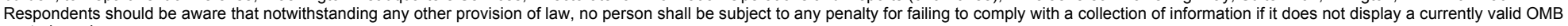
control number.

PLEASE DO NOT RETURN YOUR FORM TO THE ABOVE ADDRESS.

\section{REPORT DATE (DD-MM-YYYY) \\ 2. REPORT TYPE \\ 3. DATES COVERED (From - To)}

01-03-2009

\section{TITLE AND SUBTITLE}

Technical Memorandum

Concept, Simulation, and Instrumentation for Radiometric Inflight Icing Detection

5a. CONTRACT NUMBER

5b. GRANT NUMBER

5c. PROGRAM ELEMENT NUMBER

\section{AUTHOR(S)}

Ryerson, Charles, C.; Koenig, George, G.; Reehorst, Andrew, L.; Scott, Forrest, R.

\section{5d. PROJECT NUMBER}

5e. TASK NUMBER

5f. WORK UNIT NUMBER

WBS 609866.02.07.03.04

8. PERFORMING ORGANIZATION

REPORT NUMBER

E-16692

National Aeronautics and Space Administration

John H. Glenn Research Center at Lewis Field

Cleveland, Ohio 44135-3191

\section{SPONSORING/MONITORING AGENCY NAME(S) AND ADDRESS(ES)}

National Aeronautics and Space Administration

Washington, DC 20546-0001

\section{SPONSORING/MONITORS ACRONYM(S) \\ NASA \\ 11. SPONSORING/MONITORING REPORT NUMBER \\ NASA/TM-2009-215519}

\section{DISTRIBUTION/AVAILABILITY STATEMENT}

Unclassified-Unlimited

Subject Categories: 03, 35, and 47

Available electronically at http://gltrs.grc.nasa.gov

This publication is available from the NASA Center for AeroSpace Information, 301-621-0390

\section{SUPPLEMENTARY NOTES}

\section{ABSTRACT}

The multiagency Flight in Icing Remote Sensing Team (FIRST), a consortium of the National Aeronautics and Space Administration (NASA), the Federal Aviation Administration (FAA), the National Center for Atmospheric Research (NCAR), the National Oceanographic and Atmospheric Administration (NOAA), and the Army Corps of Engineers (USACE), has developed technologies for remotely detecting hazardous inflight icing conditions. The USACE Cold Regions Research and Engineering Laboratory (CRREL) assessed the potential of onboard passive microwave radiometers for remotely detecting icing conditions ahead of aircraft. The dual wavelength system differences the brightness temperature of Space and clouds, with greater differences potentially indicating closer and higher magnitude cloud liquid water content (LWC). The Air Force RADiative TRANsfer model (RADTRAN) was enhanced to assess the flight track sensing concept, and a "flying" RADTRAN was developed to simulate a radiometer system flying through simulated clouds. Neural network techniques were developed to invert brightness temperatures and obtain integrated cloud liquid water. In addition, a dual wavelength Direct-Detection Polarimeter Radiometer (DDPR) system was built for detecting hazardous drizzle drops. This paper reviews technology development to date and addresses initial polarimeter performance.

\section{SUBJECT TERMS}

Aircraft icing; Microwave radiometers; Aircraft hazards; Cloud physics; Millimeter wave; Radiometry; Icing; Polarimeter;

RADTRAN; Liquid water content; Neural network

\begin{tabular}{|l|l|l|l|c|}
\hline \multicolumn{2}{|l|}{ 16. SECURITY CLASSIFICATION OF: } & $\begin{array}{l}\text { 17. LIMITATION OF } \\
\text { ABSTRACT }\end{array}$ & $\begin{array}{c}\text { 18. NUMBER } \\
\text { OF } \\
\text { PAGES }\end{array}$ \\
\begin{tabular}{|l|l|l|} 
a. REPORT \\
U
\end{tabular} & $\begin{array}{l}\text { b. ABSTRACT } \\
\text { U }\end{array}$ & $\begin{array}{l}\text { c. THIS } \\
\text { PAGE } \\
\text { U }\end{array}$ & UU & 20 \\
\end{tabular}

19a. NAME OF RESPONSIBLE PERSON
STI Help Desk (email:help@sti.nasa.gov)
19b. TELEPHONE NUMBER (include area code)
301-621-0390



